\title{
Técnicas de projeto de controladores para uma suspensão ativa
}

\author{
$\underline{\text { Reginaldo Cardoso }} \quad$ Magno Enrique Mendoza Meza \\ Universidade Federal do ABC - Centro de Engenharia, Modelagem e Ciências Sociais Aplicadas - \\ Engenharia de Instrumentação, Automação e Robótica \\ Av. dos Estados 5001, Bangu, SP09210-580, Campus Santo André, São Paulo, Brasil \\ E-mail: reginaldo.cardoso@ufabc.edu.br; magno.meza@ufabc.edu.br
}

\section{RESUMO}

Este trabalho foca-se na simulação, implementação e comparação de quatro técnicas de controle aplicadas a um quarto do sistema de suspensão ativa com dois graus de liberdade, Figura 1, sistema de suspensão ativa da Quanser ${ }^{\circledR}$. O modelo da suspensão ativa consiste em duas massas, cada uma delas é sustentada por uma mola e um amortecedor. Uma das massas representa um quarto da massa da carroceria $\left(M_{s}\right)$ e a outra representa a roda $\left(M_{u s}\right)$. Entre as massas, localiza-se a suspensão ativa, que é representada por uma mola, um atuador (um servomotor) e um amortecedor. Uma mola e um amortecedor posicionados paralelamente simulam a rigidez do pneu em contato com o solo [2].

Para a representação da força presente em cada elemento da suspensão foi utilizado o deslocamento relativo, onde a constante da mola $\left(K_{S}\right)$ multiplicada pelo deslocamento relativo entre a carroceria $\left(Z_{s}\right)$ e a roda $\left(Z_{u s}\right)$ representa a força da mola e a constante de amortecimento do amortecedor $\left(B_{S}\right)$ multiplicado pela diferença relativa entre a velocidade da carroceria $\left(\dot{Z}_{s}\right) \mathrm{e}$ da roda $\left(\dot{Z}_{u s}\right)$ representa a força do amortecedor. A representação da força dos pneus pode ser feita usando um sistema igual ao de uma suspensão passiva, amortecedor passivo $\left(B_{u s}\right)$ mais uma mola $\left(K_{u s}\right)$, assim, a representação da força devido à rigidez do pneu é dada pela diferença entre a posição $\left(Z_{r}\right)$ e a velocidade das irregularidades da pista $\left(\dot{Z}_{r}\right)$ e da roda. Obtendo, assim, a representação por variáveis de estado: $\dot{x}=A x+B u, y=C x+D u$, veja Equações (1).

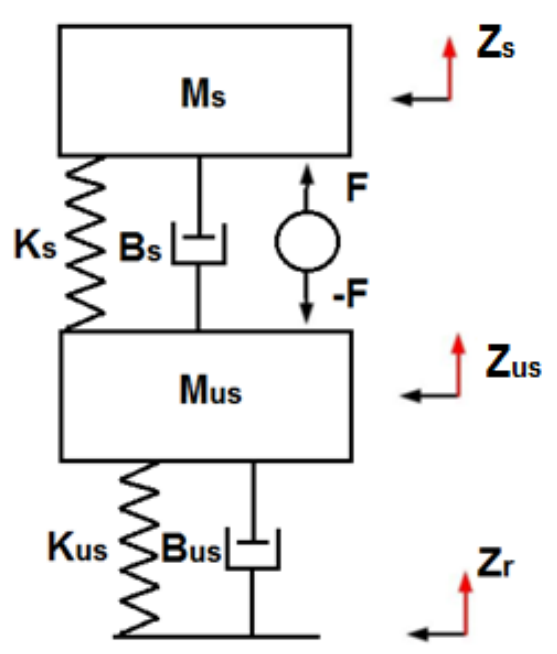

Figura 1 - Modelo quarter-car [2].

$$
\begin{gathered}
\mathrm{A}=\left[\begin{array}{cccc}
0 & 1 & 0 & -1 \\
\frac{-K_{s}}{M_{s}} & \frac{-B_{s}}{M_{s}} & 0 & \frac{B_{s}}{M_{s}} \\
0 & 0 & 0 & 1 \\
\frac{K_{s}}{M_{u s}} & \frac{B_{s}}{M_{u s}} & \frac{-K_{u s}}{M_{u s}} & -\frac{B_{s}+B_{u s}}{M_{u s}}
\end{array}\right], \\
\mathrm{B}=\left[\begin{array}{cc}
0 & 0 \\
0 & \frac{1}{M_{s}} \\
-1 & 0 \\
\frac{B_{u s}}{M_{u s}} & -\frac{1}{M_{u s}}
\end{array}\right], \mathrm{C}=\left[\begin{array}{cccc}
1 & 0 & 0 & 0 \\
-\frac{K_{s}}{M_{s}} & -\frac{B_{s}}{M_{s}} & 0 & \frac{B_{s}}{M_{s}}
\end{array}\right],(1) \\
\mathrm{D}=\left[\begin{array}{cc}
0 & 0 \\
0 & \frac{1}{M_{s}}
\end{array}\right], x=\left[\begin{array}{c}
Z_{s}-Z_{u s} \\
\dot{Z}_{s} \\
Z_{u s}-Z_{r} \\
\dot{Z}_{u s}
\end{array}\right], u=\left[\begin{array}{c}
\dot{Z}_{r} \\
F
\end{array}\right], \\
y=\left[\begin{array}{c}
Z_{s}-Z_{u s} \\
\ddot{Z}_{s}
\end{array}\right] .
\end{gathered}
$$

$\mathrm{O}$ objetivo dos controladores é reduzir o excesso de vibração na carroceria. $\mathrm{O}$ primeiro dos controles propostos é uma realimentação de estados observados, no qual o observador é de ordem plena. Apesar do sistema de suspensão ativa da Quanser ${ }^{\circledR}$ ter todas as suas variáveis de estado disponíveis, optou-se por fazer o observador, pois do ponto de vista prático, não está disponível na maioria dos casos. 
Com o observador de ordem plena projetado optou-se por desenvolver um controlador skyhook, pois se utiliza a velocidade da carroceria e da roda que são estados obtidos do observador. No estado velocidade da carroceria, aplica-se um ganho que representa o coeficiente de amortecimento do amortecedor fictício. A ideia principal é imaginar um amortecedor ligado entre a carroceria e um céu imaginário, assim, a realimentação e feita com a força resultante entre o amortecedor imaginário e o amortecedor da suspenção [3].

Devido a grande presença de controladores fuzzy (do tipo Mandani) em suspensões semiativas [1], foi desenvolvido um controlador do mesmo tipo para a suspensão ativa. As entradas do fuzzy são a velocidade relativa entre as massas e a velocidade da carroceria e como saída, a força. Foi escolhida esta abordagem devido ao fato que as saídas do sistema são a posição relativa entre as massas e a aceleração da carroceria, desta maneira derivando e integrando-as, respectivamente, não foi necessário o uso do observador.

Em comparação com os controladores projetados, utilizou-se também o controlador do tipo LQR (Linear Quadratic Regulator), que foi projetado pelo fabricante do equipamento.

Com os resultados das simulações e das implementações no equipamento, foram comparados os parâmetros de desempenho $M_{p}[\%]$ máximo sobressinal em porcentagem e $t_{s}$ tempo de acomodação, como mostrado na Tabela 1 .

Tabela 1 - Comparação entre os

\begin{tabular}{|c|c|c|c|c|}
\cline { 2 - 5 } \multicolumn{1}{c|}{ Tabela 1 - Comparação entre os } & \multicolumn{2}{|c|}{ Simulação } & \multicolumn{2}{c|}{ Implementação } \\
\cline { 2 - 5 } \multicolumn{1}{c|}{ controladores. } & $M_{p}[\%]$ & $t_{s}[\mathrm{~s}]$ & $M_{p}[\%]$ & $t_{s}[\mathrm{~s}]$ \\
\hline Realimentação de estados observados & 35 & 0,617 & 52 & 0,605 \\
\hline Skyhook & 55 & 0,758 & 68 & 1,031 \\
\hline Fuzzy & 21 & 0,576 & 57 & 0,576 \\
\hline LQR & 17 & 0,571 & 25 & 0,521 \\
\hline
\end{tabular}

Devido à presença de ruído dos sensores, os resultados implementados foram maiores que o simulado. O LQR apresentou um menor máximo sobressinal de todos, veja Tabela 1, um tempo de acomodação baixo dentre todos os controladores, mas não se mostrou muito eficiente quanto ao quesito dirigibilidade já que a roda apresentou uma resposta muito oscilatória.

Os controladores por realimentação de estado e o skyhook apresentaram um máximo sobre sinal e tempo de acomodação superior ao LQR, conforme Tabela 1. O principal problema, destes dois controladores foi à limitação imposta pelo equipamento, onde o ganho do observador não pode ser muito elevado, fazendo com que o observador não apresente uma resposta rápida o suficiente.

O fuzzy apresentou uma resposta muito parecida com o LQR, pois ambos tiveram um aumento no máximo sobre sinal, mas praticamente manteve o mesmo tempo de acomodação. Considerando a complexidade do projeto, já que o LQR é muito mais complexo matematicamente de se desenvolver que o fuzzy, pois o fuzzy é mais intuitivo e para desenvolvêlo basta entender o funcionamento da suspensão.

Palavras-chave: Suspensão Ativa, Controle Fuzzy, Realimentação de Estados, Observador de Ordem Completa, Skyhook, LQR.

\section{Referências}

[1] E. F. Paschoal, "Controle Semi-Ativo de Vibrações Usando Lógica Nebulosa e Fluido Magnetoreológico”, Tese de Mestrado, Faculdade de Engenharia, Unesp, 2011.

[2] QUANSER INNOVATE EDUCATE. Active suspension control laboratory - Instructor manual. Revision 2.0. Quanser Innovate Educate 48p. 2010. (Document Number, 845)

[3] R. L. de Sá, “Controle Skyhook Aplicado a um Modelo de Suspensão Hidropneumática para Carretas Agrícolas”, Tese de Mestrado, Faculdade de Engenharia Mecânica, UNICAMP, 2008. 